\title{
Journal of Business, Economics and Finance
}

\section{EFFICIENCY OF THE MINMAX PORTFOLIO ON THE EUROPEAN CAPITAL MARKET - CAN WE BEAT THE MARKET?}

DOI: 10.17261/Pressacademia.2017.497

JBEF- V.6-ISS.2-2017(3)-p.78-87

\author{
Almira Arnaut-Berilo ${ }^{1}$, Azra Zaimović ${ }^{2}$, Mirza Šikalo ${ }^{3}$ \\ ${ }^{1}$ University of Sarajevo, School of Economics and Business, Sarajevo. almira.arnaut@efsa.unsa.ba \\ ${ }^{2}$ University of Sarajevo, School of Economics and Business, Sarajevo. azra.zaimovic@efsa.unsa.ba \\ ${ }^{3}$ University of Sarajevo, School of Economics and Business, Sarajevo.mirzasikalo@hotmail.com
}

To cite this document

Arnaut-Berilo, A., A. Zaimovic and M. Sikalo (2017). Efficiency of the minmax portfolio on the European capital market - can we beat the market? Journal of Business, Economics and Finance (JBEF), V.6, Iss.2, p.78-87

Permemant link to this document:http://doi.org/10.17261/Pressacademia.2017.497

Copyright: Published by PressAcademia and limited licenced re-use rights only.

\section{ABSTRACT}

Purpose- This paper presents game theory approach for solving problem of the optimal investment portfolio selection.

Methodology- Model was formed on the basis of historical returns on stocks presented as a matrix of payments. The goal is seeking the minimum between the largest potential losses, and therefore it is called minmax model. The main objective is to answer whether the minimax model tool performs better than the stock market index, and to verify the relationship between the established Markowitz meanvariance (MV) efficient portfolios and minmax optimum portfolio. We use data from the European capital market and Euro Stoxx 50 index as a reference index in the period 2004-2015, which we divided into two parts. We compared and analyzed the performance of the portfolios created through minimax model with the performance of market index and MV model in the actual investment period and it proved to be dominant and more successful.

Findings- Results speak in favor of minmax portfolio model as effective passive investment strategy. It is possible to maximize returns over even longer periods of up to year without changing portfolio investments, i.e. without frequent trading and not just to gain market return, but to beat the market by this technical investing.

Conclusion- Minmax model could be used for asset allocation in portfolio investments and that there is a real possibility to beat the market using minimax model.
\end{abstract}

Keywords: Portfolio optimization, game theory, linear programming, efficiency, indices JEL Codes: C61, C72, G11, G32

\section{INTRODUCTION}

The problem of portfolio optimization is one of the central problems in finance. The main objective is to create a portfolio with the highest return on investment at an acceptable level of risk. By the middle of the last century, the portfolio choice was based on subjective criteria or investors preferences and intuition. This is followed by a modern stage of portfolio theory in which emphasis was placed on the assessment of the portfolio risks and investor's aversion to risk. Markowitz (1952) explains the portfolio space as space defined by the return and risk where return is measured as mean return of investment and risk is measure as square root of variance of returns. A model based on Markowitz measures of return and risk is called mean-variance model. Although we have a lot of research papers in this area, there are still open questions of risk measurement, determining the link between risk and return and the effectiveness of passive investment portfolio strategies. In this paper we propose an optimal portfolio selection based on game theory, where the investment is presented as a non-cooperative normal-form game a two-player zero-sum; on one side is an investor that is trying to achieve as large as possible expected return, and on the other side we have the market that generates various yields and that imposes limitations to the investor. In order to solve this matrix game we have formed linear programming model with 
the aim to minimize the maximum possible loss. As a measure of risk in the model we use the maximum losses recorded through a matrix of payments. Our empirical tests are made with stocks from the European capital market. This market is liquid and efficient, what enables us to make general conclusions about the functionality of the model. The main objective of this paper is to answer the question whether the minimax model tool allows achieving better performances than the market share index on the European capital market, and what is the relationship between minmax portfolio and efficient portfolio in terms of Markowitz definitions. The paper compares the actual realization of minmax optimal portfolio, selected MV-efficient portfolios and the share index EURO STOXX 50 in two periods: 2004-2008 (the period before the crisis and during the crisis) and 2009-2014 (market recovery).

The paper is divided into five parts. Section 2, literature review provides an overview of theoretical background of the most important models for the optimization of the portfolio with regard to risk. Section 3 explains the methodology used for the analysis and the data. The results of minmax model and performance analysis are given in Section 4 . Finally, brief summary and concluding remarks are given in Section 5.

\section{LITERATURE REVIEW}

Basics of modern portfolio theory were set by Harry M. Markowitz (1952) using mean-variance (MV) model. Model is based on average return, and variance/standard deviation as a measure of risk. Risk of portfolio is now the central element of the portfolio theory, and relationship of stock returns in the portfolio, described through covariance, becomes of crucial importance. In the essence of Markowitz's theory is the idea that, for the given level of risk, rational investor picks the portfolio which brings the highest returns, or vice versa, for the given level of return, selects the portfolio with the lowest risk. Only portfolios which fulfill the above stated criteria can be chosen, and all the others are considered as inefficient. Despite the great theoretical accuracy, MV model is not the best choice for selection of portfolio due to difficulties with formulating and solving it.

The most important criticism of MV model is related to the use of standard deviation as a measure of risk and the complexity of quadratic programming arising from it. Because of that, after Markowitz, a number of authors have tried to simplify the problem of portfolio optimization and bring it down to the problem of linear programming. All those models are based upon the same principle - minimizing the risk, no matter how it is defined. Thus, they are named mean-risk models (Sharma and Mehra 2013), and they observe the risk in the following two ways: as a dispersion of realized returns from expected returns or as a possibility of gaining the largest loss. The first one includes standard deviation, absolute mean and other similar measures, and the others include minimax model, Value at Risk (VaR), Conditional Value at Risk (CVaR) and similar.

William Sharpe (1971) has created a one-factor model as a linear approximation of MV model. The main idea was that return of any stock in time $t$ is described as a linear function of some index which represents the effect of the whole market (proxy for market portfolio) and a good enough approximation of its movement. Soon, the model in which one factor affects returns was widened and a multifactor model was introduced (Chen, Roll and Ross, 1986). Factor models explain the effects of diversification. Konno and Yamazaki (1991) use mean-absolute deviation (MAD) of returns as a measure of risk. This way, they substitute variance, which represents a quadratic deviation, with the absolute one, thus transforming quadratic utility function into linear one. With assumption of normal distribution, as with Markowitz's model, minimization of mean-absolute deviation will show similar results as when using variance as a measure of risk. Optimal portfolio is the one which minimizes mean-average deviation of returns for the given level of return, and the constraints are equal to the constraints of the MV model. MAD model ignores the covariance, which decreases the possibility of diversification. In the periods of financial crises, correlation coefficients converge to 1 and the benefits of diversification diminish (Campbell, Koedijk, Kofman, 2002, Konno and Yamazaki, 1991), so in the events of the whole market declines, they state that correlations between stocks become irrelevant, and that MAD model is justified.

Young (1998) presented minimax model which has the goal of maximizing minimal returns during all observed periods with the constraint of minimum accepted average return in that period. In this model, minimum returns are used as a measure of risk. With goal function set up like this, the problem of quadratic utility function, which exists with MV model, is now solved. For normal distribution, results will be similar to the ones calculated using the MV model. Sharma and Mehra (2013) combine both types of risk measurement in the model of portfolio optimization. They have set up the model with the goal of minimizing variations around the expected value, but at the same time, setting up the constraint which conditions the realization of the better result from the worst possible for each period. Instead of using variance, they use half of the meanaverage deviation as a measure of dispersion. Thus, minimax model is used for formulating security measures and half of the mean-average deviation as a stability measure. Benati and Rizzi (2007) have based their model on the Markowitz's, but they have substituted variance as a measure of risk with the value at risk (VaR). Authors have presented that the posed problem can be solved using CPLEX in rational time if the number of observed periods and the number of assets are not too large. Angelelli, Mansini and Speranza (2008) have created two more models which include transaction costs, minimum number of transactions and cardinal constraints. The first one is based on maximization of the worst conditional value of 
risk (CVaR), and the other on minimization of mean-average deviation. First model (CVaR) has shown to be more successful in terms of the level of returns and their stability. However, it is much more complicated and it requires more time to get the solution. Ferreira, Filho and Sousa (2009) use the decision theory for optimization of portfolio. Expected losses are the measure of risk, and they conduct their analysis using Bayes theorem. Model is brought down to the game theory, and considering that there is no variance as a measure of risk, they use linear utility function.

\section{DATA AND METHODOLOGY}

\section{1. Theoretical Framework}

Optimal portfolio selection decision can be explained with influence diagram. In order to comprehend the elements that have influence on the investors' choice and success of his decisions we have formed influence diagram presented in Figure 1.

Figure 1: Influence Diagram

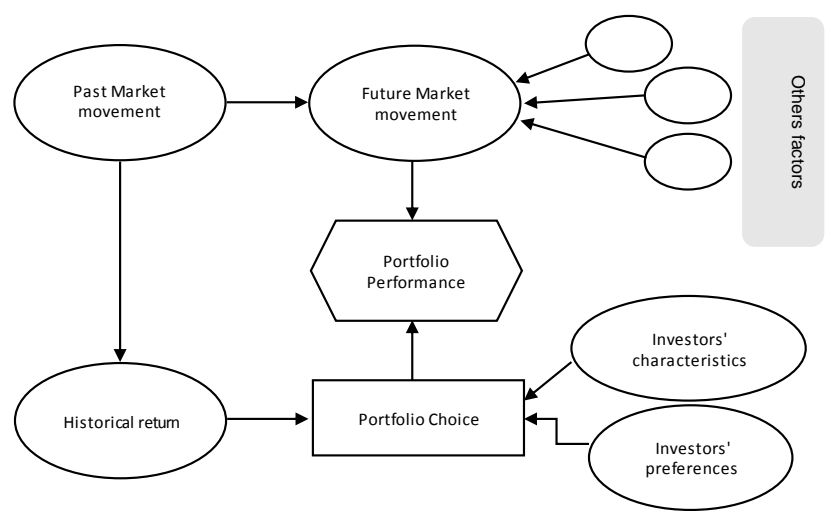

From the diagram we see that attempt to measure and evaluate the risk factors presented in the chances of nodes actually define different models for optimal portfolio. Game theory approach assumes that historical return present payment matrix with investor as first player and market as a second player. Strategies that an investor has available are investments in stocks of various issuers, while repeating the behavior of the past represents a strategy for market. For example, each stock represents one possible strategy for investors, and each month in observed period represents one market strategy.

Payoff matrix (1) contains historical returns of selected stocks increasing by 1 , in order to provide positive expected game value ${ }^{1}$, where $A_{i}$ presents observed $m$ different stocks (strategies for investors) and $B_{j}$ presents $n$ different market states.

$$
\begin{aligned}
& \begin{array}{llllll}
\mathrm{B}_{1} & \mathrm{~B}_{2} & \cdots & \mathrm{B}_{\mathrm{j}} & \cdots & \mathrm{B}_{\mathrm{n}}
\end{array} \\
& \begin{array}{c}
A_{1} \\
A_{2} \\
\cdots \\
A_{i} \\
\cdots \\
A_{m}
\end{array}\left[\begin{array}{cccccc}
a_{11} & a_{12} & \cdots & a_{1 j} & \cdots & a_{1 n} \\
a_{21} & a_{22} & \cdots & a_{2 j} & \cdots & a_{2 n} \\
\cdots & \cdots & \cdots & \cdots & \cdots & \cdots \\
a_{i 1} & a_{i 2} & \cdots & a_{i j} & \cdots & a_{i n} \\
\cdots & \cdots & \cdots & \cdots & \cdots & \cdots \\
a_{m 1} & a_{m 2} & \cdots & a_{m j} & \cdots & a_{m n}
\end{array}\right] \equiv\left[a_{i j}\right]
\end{aligned}
$$

Solving matrix game means determining the investments vector $p=\left[p_{i}\right]_{m \times 1}$, where $p_{i}$ present probability for selection strategy $i$. This vector is solution of linear programming model (2) to (4).

$$
\begin{gathered}
\min (g)=\sum_{i=1}^{m} y_{i} \text { za } g=\frac{1}{V} \\
\sum_{i=1}^{m} a_{i j} \cdot y_{i} \geq 1, \quad j=\overline{1, n} \\
y_{i} \geq 0, \quad i=\overline{1, m}
\end{gathered}
$$

\footnotetext{
${ }^{1}$ Condition for the use of linear programming in zero sum games is the assumption of positive payment matrix.
} 
Decision variable in the model is $y_{i}$, where $y_{i}=\frac{p_{i}}{V}$. Value $a_{i j}$ - return on a security $i$ in the period $j$. Value of the game present the lowest expected value of the portfolio formed from the model assuming that historical data reflect well expectations. This value is $V-1$ and is calculated from reciprocal value of goal function $g$ in the model. Young (1998), on a similar basis, develop their minmax model that adds a limitation of the lowest acceptable yield, explains the possibility of introducing transaction costs and tax in the model. This model can be expanded by adding conditions of maximum investment in a single action.

The classical Markowitz portfolio model is used to determine the efficient risk-return combination, i.e. efficient frontier $(E F)^{2}$. This model includes historical return, preferences of investors and their characteristics (three chance nodes from Figure 1). Efficient frontier is convex curve and lies between the portfolio with minimal standard deviation and the portfolio with maximum rate of return (mean). Model includes portfolio expected return $\bar{R}_{p}$ and portfolio variances $\sigma_{p}{ }^{2}$ where investments satisfy the investment constraints: $\sum_{i=1}^{n} x_{i}=1$ and no negativity conditions. If the investor considers investing in a portfolio, with a pre-determined value of expected return on investment $E$, we have additional constraint $\sum_{i=1}^{n} \bar{R}_{i} x_{i}=E$ (model $\left.5-7\right)$.

$$
\begin{gathered}
\min \sigma_{P}^{2}=\sum_{i=1}^{n} \sum_{j=1}^{n} x_{i} x_{j} \operatorname{Cov}\left(R_{i}, R_{j}\right) \\
\sum_{i=1}^{n} \bar{R}_{i} x_{i}=E \\
\sum_{i=1}^{n} x_{i}=1 ; x_{i} \geq 0, \quad i=\overline{1, n}
\end{gathered}
$$

As a result, model present the investment vectors that provide the absolutely minimum portfolio return variance $\sigma_{\min }^{2}$ with the pre-set return $E$. By choosing randomly expected return of investment in the range $\bar{R}_{\text {min }} \leq E \leq \bar{R}_{\text {max }}{ }^{3}$ we can determine the efficient set of the observed security (Arnaut-Berilo, Zaimović, 2012). Square root of portfolio variance is used as measure of portfolio risk and it includes correlations between equity return. Markowitz argued that low or negative correlations will eliminate portfolio risk, measured by $\sigma_{P}^{2}$. Models (2-4) and (5-7) have the same goal, to choose the best Portfolio according the available data. Model (2-4) is a linear programming model and the model (5-7) is quadratic programming model. These models differ in measures of risk and it is shown that at a time when returns follow a normal distribution, these two measures of risk will give approximately the same results (Young (1998)). If returns are not normally distributed mean variance model, by theoretical assumptions, cannot be applied. For minimax model there is no assumption about normal data distributions. Note that the minimax model is sensitive to extreme values of the historical returns.

\section{2. Data}

We use stock returns data from European capital market, observed in 11-year period, from 2004 till 2014. The sample is consisted of stocks from stock market index Euro Stoxx 50, and those are stocks from 13 different sectors and 7 different countries. Two stocks from this index were omitted from our sample: Inditex and Unibail-Rodamco ${ }^{4}$. The sample is in line with the composition of the index at the beginning of 2016. We assume that Euro Stoxx 50 index is a good approximation of movement of the whole market and it will be used as a benchmark index for the comparison of portfolio performances of our model. The EURO STOXX 50 Index as a Europe's leading blue-chip index for the Eurozone provides a blue-chip representation of supersector leaders in the Eurozone. The index covers 50 stocks from 11 Eurozone countries. It is designed in a way that it best describes the overall market movements, and therefore can be considered an adequate substitute for the market portfolio. In fact, the Euro Stoxx 50 is derived from the 19 sectoral indices of the Eurozone and includes stocks whose market value makes about $60 \%$ of their countries total market capitalization (Stoxx Limited, 2016.).

\footnotetext{
${ }^{2}$ The mean-variance combination of a portfolio is efficient if there are no other combinations with the same return, and a lower variance, or the same variance and higher return.

3 If the following is true $E>\bar{R}_{\text {max }}$ the model would be unsolvable, and if $E<\bar{R}_{\min }$ then the solution to the system (5- 7) would not be an element of the efficient set, where $\bar{R}_{\min }$ and $\bar{R}_{\max }$ corresponds to the efficient portfolio with the lowest variance and maximum return, respectively.

${ }^{4}$ In certain periods of time, Inditex did not have the sufficient level of trade. Unibail-Rodamco was founded in 2007 , so there is a problem of short trading history.
} 
Expected daily return for each stock was calculated based on historical changes in stock prices. Prices were sourced from electronic platform of trading system Xetra. Average daily return in a particular month is simply the arithmetic mean of all daily returns in that month. The selected benchmark index is not corrected for dividends, as well as the analyzed models. We divide the observed period into two sub-periods; from January 2004 until December 2008 and from January 2009 until December 2014. The first period covers time before and during the recent financial crises. The second period is a time of market recovery from the crisis. Due to the fact that we observe average daily returns on a month level, in the first period we have 60 periods and in the second one we have 72 periods. Real performances of optimal portfolios for both periods were measured in the verification periods. Thus, for the first portfolio, the year 2009 will be considered as a real investment period, while for the second one that will be the year 2015.

\section{FINDINGS AND DISCUSSIONS}

\section{1. Forming Portfolios}

By applying minimax model on stock returns in period from 2004 to 2008 we obtained portfolio denoted with P1. Optimal structure of the portfolio P1 is presented in Figure 2 . Value V is $-0.0691 \%$ and it represents minimal portfolio return during that period. No matter what scenario really happens, loss would not be larger than the $0.0691 \%$ on invested. From the viewpoint of minimax model this is the total risk that investor is willing to take. It is important to note that this conclusion hold true only if historical data is a good representative of the future.

Figure 2: The Structure of the Portfolio P1

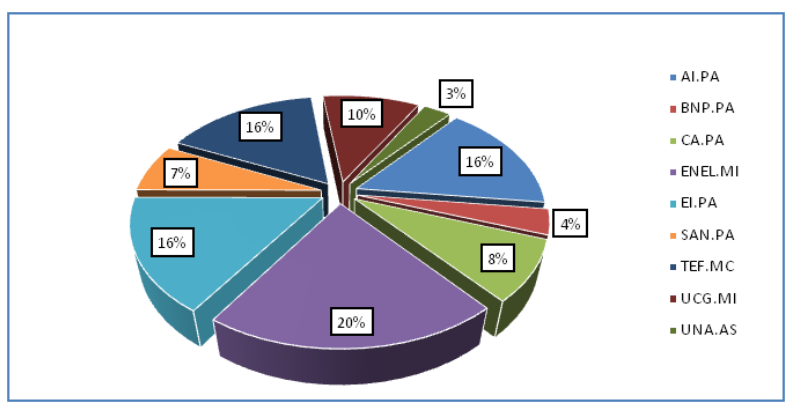

Optimal portfolio P1 is consisted of nine stocks. Although we did not set up any constraints, neither one of the stocks weights more than $20 \%$ of portfolio. This number of stocks, with relatively equal weights of all stocks in the portfolio, makes it theoretically acceptable for investment. Four stocks in this portfolio have negative expected returns. Based on that, we can see that this model does not entirely prioritize stocks with high positive returns, like MV model does. Portfolio includes stocks of companies from 6 different sectors and 4 different countries. Created portfolio, in mean-variance space and for the period 2004- 2008, would have the following characteristics: average portfolio daily return is $0.0458 \%$ and its' standard deviation is $1.0341 \%$. To make it easier to compare, we will correct monthly data for annual by multiplying it with number of trading days in one year, so the expected annual portfolio return is $\hat{\mathrm{R}}=11.44 \%$ and its' standard deviation is $\hat{\sigma}=16.35 \%$.

Figure 3: The Structure of the Portfolio P2

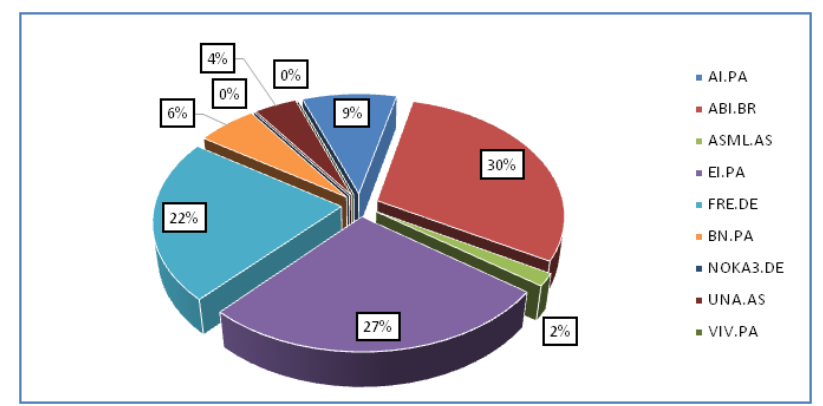

We created the second portfolio (P2) based on stock returns in period $2009-2014$. Value of the goal function is $-0.08427 \%$. From the viewpoint of minimax model, maximum loss is larger in this case than with the first portfolio. Thus, we can conclude that this portfolio has larger risk from the viewpoint of minimax model, i.e. maximum possible loss. In this case, accidently we also have nine stocks in the portfolio. However, just three stocks make up $79 \%$ of the portfolio and weights of two stocks are so low they can be ignored. Unlike the first portfolio, most of stocks in P2 have positive returns. Even though P2 evidently has larger concentration of investment in lower number of stocks compared to P1 portfolio, portfolio P2 can 
be considered acceptable for investment. It contains stocks of companies from 4 different industrial sectors and 5 different countries. Portfolio structured like this has the following characteristics in MV space: Expected daily return is $0.0891 \%$ and standard deviation $0.7539 \%$. Again, we will annualize these two parameters, so the expected annual return is $22.28 \%$ and standard deviation is $11.92 \%$.

We have tested mean-variance efficiency of portfolios P1 and P2. Figures 4 and 5 present efficient frontiers created according to MV model based of annualized historical daily stock returns in periods 2004-2008 and 2009-2014 respectively. From the graphs we can see that both portfolios are inefficient in MV space.

Next we have pointed out best performing MV efficient portfolio in both periods for further comparison and analysis. Selected portfolios have the lowest ratio of return and risk (i.e. highest variation coefficient), and on graphs they are shown as tangent of EF from the origin. In Figure 3 that portfolio is denoted as portfolio M1. Expected return of this portfolio is $15.95 \%$ with standard deviation of $12.62 \%$, and it consists of 14 stocks. However, 5 of them have so low weights in the portfolio that they can be ignored, i.e. sum of their weights is lower than $0.0002 \%$. None of the stocks weights is larger than $20 \%$. In terms of sectors, portfolio consists of 10 different sectors, but weights of 4 of them can be ignored. We can conclude that there are no sectors that dominate the portfolio. Same as with portfolio P1, 9 stocks from portfolio M1 have significantly high weights. Considering that weights of those 9 stocks are quiet similar in both portfolios, and that there is similar sector diversification, better standard deviation of portfolio M1 results from lower correlation coefficients between stocks in portfolio M1, i.e. from Markowitz diversification.

Figure 4: Efficient Frontier for Period 2004-2008

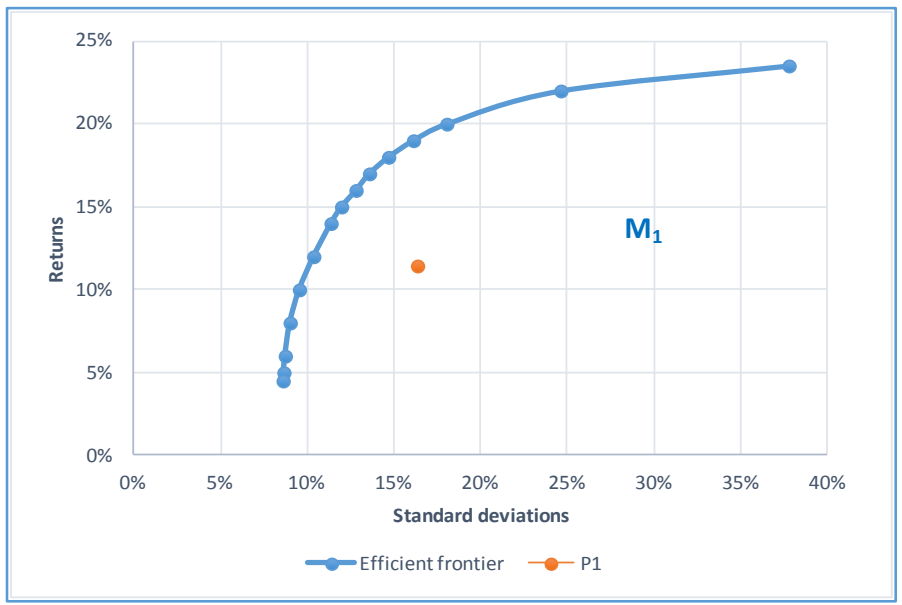

At the same time, mean return of Euro Stoxx 50 index measured as a annualized mean of index daily value changes was ($0.31 \%)$, for the same period, i.e. $2004-2008$. We will use this return as market index expected return for 2009. Considering that this is annualized daily return, we can conclude that very low negative return occurs.

All stocks that have statistically high weights in portfolio M1 had positive average daily returns in the observed period (2004-2008), even though, in this period, the number of stocks with negative returns was higher. That comes from the fact that MV model prioritizes stocks with high expected returns and low or negative correlation coefficients. The possibility of investing in stocks with negative expected returns and stocks with high correlation coefficients in MV model is lowered.

The same methodology was repeated for the next sub-period, from 2009 until 2014 . We can see that the efficient frontier lies higher, i.e. expected returns are higher for the given level of standard deviation in this period compared to the previous one. That is the consequence of the aforementioned differences in stages of market movements in two sub-periods, where period from 2009 is characterized by overall market growth and positive returns for most of the stocks.

Portfolio which has expected return $26.08 \%$ and standard deviation $11 \%$ (M2) has the highest coefficient of variation on the efficient frontier. According to MV model, this is very stable portfolio which has the possibility of earning positive return 99.11\%. ${ }^{5}$ However, the key assumption that should be fulfilled for this to hold true is the un-changeability of standard deviation, but earlier in the text we have noted that this cannot be confirmed.

\footnotetext{
${ }^{5}$ Possibility is determined using function of possibility density for normal distribution.
} 
According to minimax model, optimal portfolio P2 is inefficient, same as in the first case. However, it is much closer to the efficient frontier than in the first case. To compare, the possibility of this portfolio to earn positive returns is $96.92 \%$. Thus, almost half of the portfolios on the efficient frontier have lower coefficient of variation.

Expected return of Euro Stoxx 50 index is $6.66 \%$. If compared to period from 2004 to 2009, we can see that in this period index has shown a slight growth. The possibility for minimax optimal portfolio to earn higher return than index is $90.50 \%$.

Optimal portfolio M2 consists of 14 stocks with particular investment weights of less than $20 \%$. Four stocks have weights lower than $1 \%$, and four more stocks weights are between $1.50 \%$ and $3.25 \%$. We conclude that remaining six stocks make up $89.55 \%$ of the portfolio. In total, 14 stocks in the portfolio are from 9 different industries. Number of stocks and industries which have significant weights in both portfolios (P2 and M2) is very similar.

\section{Figure 5: Efficient Frontier for Period 2009-2014}

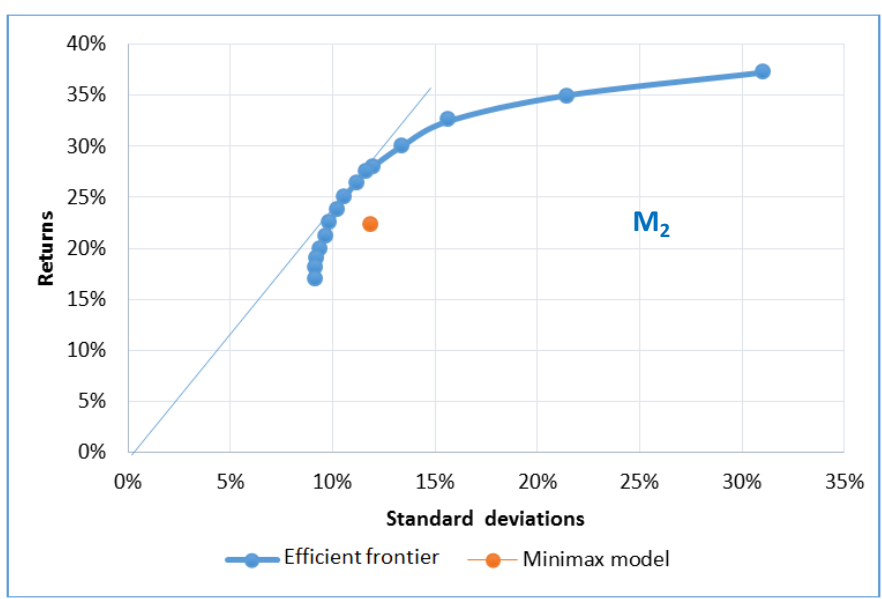

Table 1 shows aggregated results of selected portfolios in estimated periods.

Table 1: Expected Returns and Standard Deviations for P1; P2; M1 and M2

\begin{tabular}{|l|c|c|c|c|}
\hline 2004-2008 & No. of stocks & $E(\hat{R})$ & $\hat{\boldsymbol{\sigma}}$ & $\boldsymbol{k}_{v}$ \\
\hline Minimax model - P1 & 9 & $11.44 \%$ & $16.35 \%$ & 1.43 \\
\hline MV model - M1 & 14 & $15.55 \%$ & $12.62 \%$ & 0.79 \\
\hline $2009-2014$ & No. of stocks & $\boldsymbol{E}(\hat{\boldsymbol{R}})$ & $\hat{\boldsymbol{\sigma}}$ & $\boldsymbol{k}_{v}$ \\
\hline Minimax model -P2 & 9 & $22.28 \%$ & $11.92 \%$ & 0.53 \\
\hline MV model-M2 & 14 & $26.08 \%$ & $11 \%$ & 0.42 \\
\hline
\end{tabular}

Now we are able to compare structure and performances of optimal portfolios obtained using minimax model with the performances of the Euro Stoxx 50 index, as well as with results of MV model. This way, we will directly test the main hypothesis that by using minimax model we can create portfolio that beats the market stock index.

\section{2. Portfolios' Real Performance in Verification Period}

This part present real success of minimax portfolio, portfolio obtained using MV model and market index by analyzing their results in one-year verification periods for each sub-period: in year 2009 and in 2015 . We compared average daily returns during that period, as well as buy and hold investment strategy, where the success is measured as a relative difference between value of the portfolio at the end and at the beginning of the stated years.

We find that all stocks in the minimax portfolio P1 realized positive returns during 2009. Minimax portfolio earned average daily return of $0.1149 \%$, which is three times higher than expected return. When we annualize daily returns we get $28.73 \%$. If one investor implements the buy and hold strategy and creates portfolio P1 at the beginning of 2009 and sells all the stocks from the portfolio P1 at the end of that same year, one-year holding period return (calculated as relative change in price at the end of the year compared to the beginning of the year) would be $24.66 \%$. It should be noted that this level of annual return can not be compared to annualized return which we calculated earlier. In the first case we calculated relative 
daily changes and just corrected them for number of days in a year to be at the annual level. The last number represents real earnings which would be obtained by holding that portfolio during year 2009.

In year 2015, minimax portfolio P2 realized average daily return of $0.1070 \%$, or $26.75 \%$ annualized. This return is again above the expected level, but it is not as high above as in the first case. Actual one-year holding period return for portfolio P2 in 2015 is $29.25 \%$, and is even higher than annualized one.

We have analyzed performances of selected MV portfolios M1 and M2, and Euro Stoxx 50 index in same periods, 2009 and 2015. Annualized average daily returns were denoted with $\mathrm{R}$ and actual realized returns based on buy and hold strategy with $\hat{R}$. Table 2 brings those returns.

Table 2: The portfolio Performance in the Tested Periods

\begin{tabular}{|l|c|c|}
\hline 2009 & $\boldsymbol{R}$ & $\hat{\boldsymbol{R}}$ \\
\hline Minimax model - P1 & $24.66 \%$ & $28.72 \%$ \\
\hline MV model - M1 & $0.32 \%$ & $-3.93 \%$ \\
\hline Euro Stoxx 50 & $16.89 \%$ & $22.48 \%$ \\
\hline 2015 & $\boldsymbol{R}$ & $\hat{\boldsymbol{R}}$ \\
\hline Minimax model - P2 & $29.25 \%$ & $26.75 \%$ \\
\hline MV model - M2 & $23.52 \%$ & $23.46 \%$ \\
\hline Euro Stoxx 50 & $4.08 \%$ & $6.31 \%$ \\
\hline
\end{tabular}

In the first verification period, minimax model portfolio was more successful than the optimal portfolio created using MV model. However, this outperformance of minimax model compared to MV model is the result of low performance of MV optimal portfolio in 2009. Also, when compared with Euro Stoxx 50 performance, original P1 model is more successful.

Considering that different investors can select different portfolios from the efficient frontier using MV model, we also measured performances of other portfolios from the efficient frontier, testing MV model sensitivity. Considering that it is impossible to assess absolutely every point from the efficient frontier, we have tested 15 different efficient portfolios. We find that neither one of the tested portfolios has achieved better performance than portfolio P1. In addition, the best performance in year 2009 was achieved by portfolio with lowest variance. It consists of 28 stocks and it has earned a real return of $22.11 \%$. This portfolio is more similar to the minimax model than the portfolio with the highest coefficient of variation, M1. These findings enable us to conclude that regardless investors' preferences toward risk, shaped in investors' indifference curve, application of $\mathrm{MV}$ model in portfolio selection will result in lower returns compared to application of minmax model. The overall conclusion is that the domination of minimax model over the MV model is neither the result of coincidence nor bad portfolio choice from the efficient frontier.

When we compare the results of applied models in the second verification period, we find evidence that minmax portfolio has the best performance, beating the stock market index once again. During the year 2015, Euro Stock50 index real relative change was lower than expected, i.e. amounting $4.08 \%$ versus $6.31 \%$. MV portfolio realized lower returns than expected as well. On the other hand, minimax portfolio has outperformed the expected value and realized annualized return of $26.75 \%$. If we consider 2015 real return only, differences are even greater, for the benefit of portfolio P2.

In order to test sensitivity of our results to the change of MV efficient portfolios, we obtained 15 randomly selected efficient portfolios and find that none of them surpasses performance of portfolio minmax P2 in 2015. Portfolios lying in the middle part of the efficient frontier have obtained better performance, and MV efficient portfolio with expected return of $25 \%$ and standard deviation of $10.59 \%$ has shown overall dominancy over all efficient portfolios. Its' return in 2015 was $23.77 \%$. We can see that this portfolio is very similar, and is very close to the portfolio with highest coefficient of variation. The same as with that one, this portfolio consists of 14 same stocks, only their weights were slightly different. However, minimax portfolio P2 still surpasses all MV model portfolios.

In Figures 5 and 6 we can see real monthly returns derived from passive buy and hold strategy on Euro Stoxx 50 index, perceived as proxy for market return, and created minmax portfolios P1 (figure 6) and P2 (figure 7) during verification periods. 
Figure 6: Returns Movements on Euro Stoxx 50 and Minmax Portfolio P1 in 2009

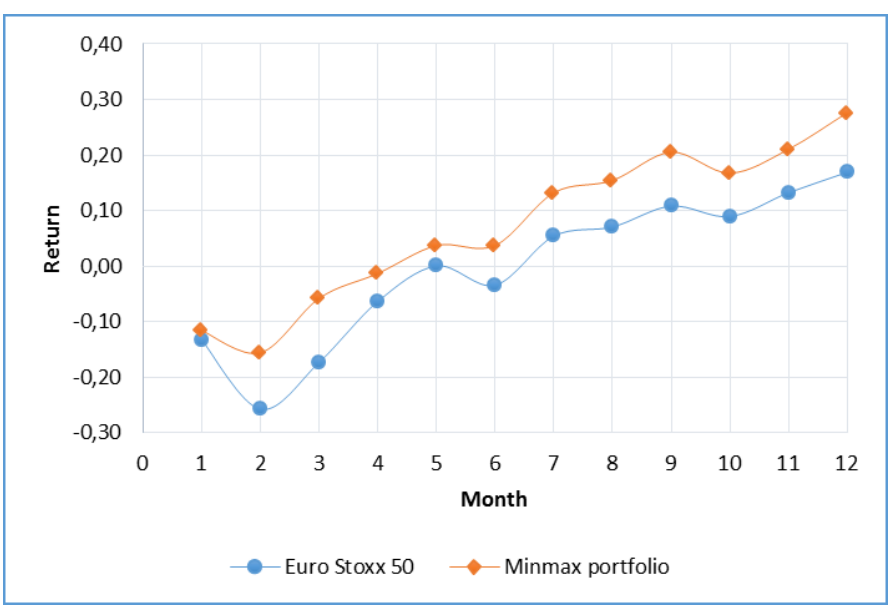

Minmax model P1 performs better than the market not just on a yearly level, but in every single month its real returns are higher than the market return. We notice high correlation between minmax portfolio and index returns in the verification period due to the same input data (returns of 48 stocks) just structured differently (minmax portfolio is a subset of Euro Stoxx 50 index with different investment weights). It is obvious that minmax model extracts from the sample the best performing stocks not just temporarily but for longer periods of up to a year, like here.

\section{Figure 7: Returns Movements on Euro Stoxx 50 and Minmax Portfolio P2 in 2015}

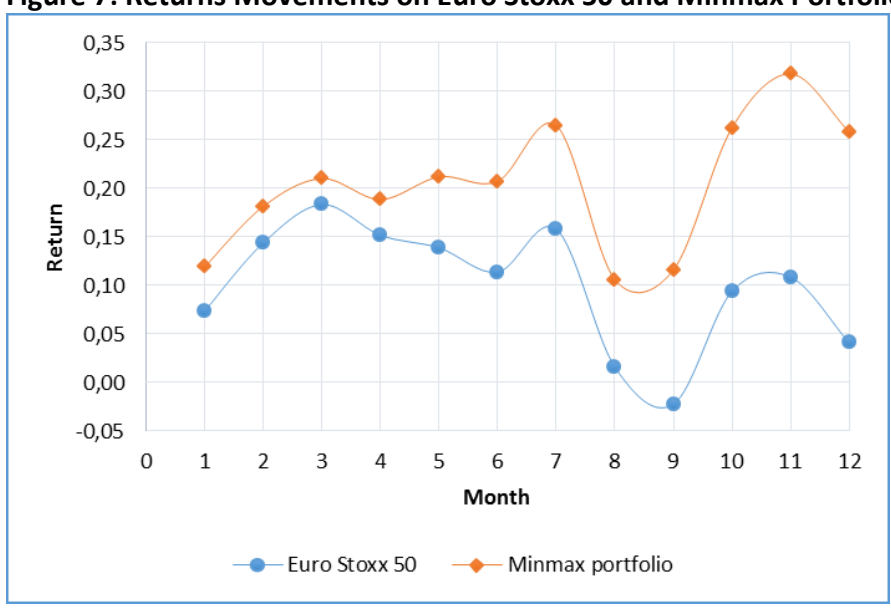

In second verification period, the domination of minimax portfolio over stock index was proven once more, again in every single month. Compared to the year 2009 return variations are now much larger.

\section{CONCLUSION}

Game theory enables us to use linear programming in solving portfolio optimization problem. The former model is based on the logic of minimization of maximum losses, so it was named minmax model. Upgrade of the basic model from game theory can be found with Young (1998). Compared to MV model, minimax model represents completely new approach to selection process because it changes some of the basic assumptions of Markowitz model. The most important change is the measurement of risk. Even though Markowitz's understanding of standard deviation as measure of risk is still the dominant one, new points of view and alternative measures which represent this phenomenon have been created for decades. Minimax model perceives risk as a fear of minimum return, i.e. highest possible loss which can be obtained by an investor.

We have applied the minmax model and analyzed its performance in European capital market. Selection of optimal portfolio was based upon sample of 48 stocks which are differentiated through sectors and countries and which create benchmark index of Eurozone - Euro Stoxx 50. We have tracked their daily returns during two periods, from 2004 until 2008, and from 2009 until 2014. Based on that data, we have created two portfolios for both periods: $\operatorname{minimax}$ (P1 and P2) and MV (M1 and M2). We have compared performances of those portfolios during real (verification) investment periods, i.e. during year 2009 for the first estimated period and in year 2015 for the second estimated period. Using minimax model 
created portfolios in both verification periods surpassed MV efficient portfolios, but also the overall market performance, i.e. minmax optimal portfolios realized higher real returns than the market index. Our results speak in favor of minmax portfolio model as effective passive investment strategy. It is possible to maximize returns over even longer periods of up to year without changing portfolio investments, i.e. without frequent trading and not just to gain market return, but to beat the market by this technical investing. We also advocate creation of investment funds tracking the minmax model portfolios, which would simplify the process of investing according to this model. We conclude that minmax model could be used for asset allocation in portfolio investments and that there is a real possibility to beat the market using minimax model.

Also, our research raises a question about adequate measure of portfolio risk - highest possible loss seems to be better measure of risk than standard deviation. Crucial advantage of this minmax measure of risk is that it does not require any specific distribution of returns. The discussion about portfolio risk continues.

\section{REFERENCES}

Arnaut-Berilo, A. and Zaimović, A., 2012. How Efficient Are Bosnian Stock Market Indexes?. Eastern European Economics, 50(1), pp.26-45.

Angelelli, E., Mansini, R., Speranza, M.G. (2008). A comparison of MAD and CVaR models with real features. Journal of Banking and Finance, 32(7), pp. 1188-1197

Benati, S., Rizzi, R. (2007). A mixed integer linear programming formulation of the optimal mean/value-at-risk portfolio problem. European Journal of Operational Research, 176(1), pp. 423-434.

Campbell, R., Koedijk, K. and Kofman, P., 2002. Increased correlation in bear markets. Financial Analysts Journal, 58(1), pp.87-94.

Chen, R., , Roll, R., Ross, N.R. (1986). Economic Forces and the Stock Market. Journal of Business, 59(3), pp. $383-403$.

Ferreira, R.J.P., Almeida Filho, A.T., Souza, F.M.C. (2009). A Decision Model for Portfolio Selection. Pesquisa Operacional, 29(2), pp. 403417.

Konno, H., Yamazaki, H. (1991). Mean-Absolute Deviation Portfolio Optimization Model and Its Applications to Tokio Stock Market. Management Science, 37(5), pp. 519-531.

Markowitz, H. (1952). Portfolio Selection, The Journal of Finance, 7(1), pp. 77-91.

Sharma, A., Mehra, A. (2013). Portfolio selection with a minimax measure in safety constraint. Optimization: A Journal of Mathematical Programming and Operations Research, 62(11), pp. 1473-1500.

Sharpe, F.W. (1971). A Linear Programming Approximation for the General Portfolio Selection Problem. Journal of Financial Quantitative Anal, 6(1), pp. 1263-1275.

Young, M.R. (1998). A Minimax Portfolio Selection Rule with Linear Programming Solution. Management Science, 44(5), pp. 673-683.

Internet pages:

Finanzen.net GmbH (2016). Stock Price. Available on: www.quotenet.com (accessed 20 ${ }^{\text {th }}$ March 2016)

Stoxx Limited (2016). EURO STOXX $50^{\circ}$ INDEX. Available on:

www.stoxx.com/document/Bookmarks/CurrentFactsheets/SX5GT.pdf (accessed $25^{\text {th }}$ May 2016)

Yahoo (2016). Historical Prices. Available on: www.finance.yahoo.com (accessed on $19^{\text {th }}$ March 2016) 